\title{
Ventricular arrhythmias complicating weight reduction therapy in a patient with a prolonged QT interval
}

\author{
J.C. O’Keefe, G.S. Butrous, D.S. Dymond, P. Littlejohns ${ }^{1}$, N. Peters ${ }^{1}$ and \\ S.O. Banim
}

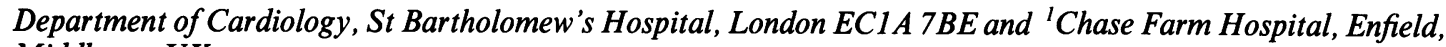
Middlesex, UK.

\begin{abstract}
Summary: Serious ventricular arrhythmias are known to occur in patients with long QT intervals. We describe a case of torsade de pointes occurring in a patient with a prolonged QT interval while taking a 1000 calorie diet, diethylpropion hydrochloride (Tenuate Dospan) and bendrofluazide. In patients with long QT intervals, hypokalaemia and drugs which further delay repolarization may facilitate the development of life threatening arrhythmias.
\end{abstract}

\section{Case report}

A 35 year old housewife presented with a $24 \mathrm{~h}$ history of brief episodes of loss of consciousness. She had been taking a 1000 calorie diet for 3 weeks; bendrofluazide $5 \mathrm{mg} / \mathrm{d}$ and diethylpropion hydrochloride $75 \mathrm{mg} / \mathrm{d}$ were added for $10 \mathrm{~d}$ prior to admission. On admission the pulse was irregular and the blood pressure was 120/ $80 \mathrm{~mm} \mathrm{Hg}$. Cardiovascular and neurological findings were otherwise normal. Biochemical investigations revealed a reduced serum potassium of $2.4 \mathrm{mmol} / 1$ (normal range $3.5-4.5 \mathrm{mmol} / \mathrm{l}$ ). All other biochemical and haematological tests were normal. The electrocardiogram revealed sinus rhythm, with frequent unimorphological ventricular ectopics. The measured QT interval $(\mathrm{QTm})$ was $0.4 \mathrm{~s}$ during a heart rate of 100 beats/min, and the corrected QT interval (QTc) according to Bazett (1920) was $0.52 \mathrm{~s}$ (normal less than $0.44 \mathrm{~s})$. The $\mathrm{QRS}$ and ST segments were normal and $\mathrm{U}$ waves were present. Chest radiograph and echocardiogram were normal.

Cardiac monitoring showed episodes of ventricular tachycardia, of a torsade de pointes morphology (Figure 1), associated with episodes of loss of consciousness. Treatment included the withdrawal of bendrofluazide and diethylpropion hydrocholoride, potassium replacement and an intravenous infusion of

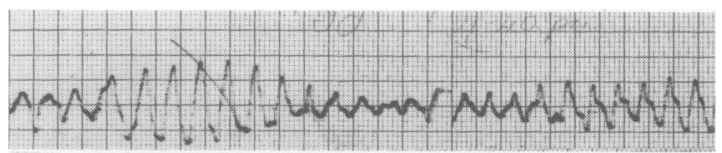

Figure 1 Torsade de pointes.

mexiletine which suppressed ventricular arrhythmias. Two days later when the patient was normokalaemic, the QTc was prolonged at $0.50 \mathrm{~s}$ (QTm, $0.42 \mathrm{~s}$, heart rate 85 beats/min) and $U$ waves were absent (Figure 2).

Three months later investigations were performed when the serum potassium was $3.9 \mathrm{mmol} / 1$. The electrocardiogram revealed that QTc was persistently prolonged to $0.48 \mathrm{~s}(\mathrm{QTm} 0.42 \mathrm{~s}$, heart rate 77 beats/ min). No ventricular arrhythmias were induced by maximal treadmill exercise testing. An intracardiac electrophysiological study revealed normal conduction times and no ventricular arrhythmias were induced with programmed right ventricular stimulation, either before or after intravenous isoprenaline $(7 \mu \mathrm{g} /$ min for $5 \mathrm{~min}$ ). The QTm during identical rates of atrial pacing was unchanged following the isoprenaline infusion. Subsequently. $100 \mathrm{mg} / \mathrm{d}$ of atenolol has shortened the QTc to $0.42 \mathrm{~s}$ (QTm $0.43 \mathrm{~s}$, heart rate 51 beats/min) and the patient has remained asymp-

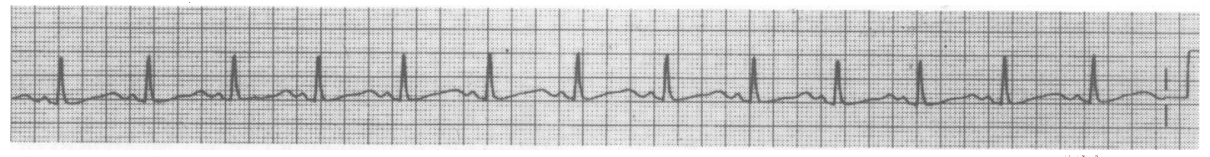

Figure 2 Shows prolonged QT interval (QTc 0.50 s) after correction of hypokalaemia.

Correspondence: J.C. O'Keefe, M.B., F.R.A.C.P.

Accepted: 15 February 1984 
tomatic during 8 months follow up. In addition 6 first degree relatives were studied and found to have normal QT intervals.

\section{Discussion}

Torsade de pointes is an atypical ventricular tachycardia which has been described in patients with congenital long QT syndromes and acquired prolonged QT intervals (Kossman, 1978; Krikler \& Curry, 1976; Soffer et al., 1982). Its association with sudden death is well known (Jervell \& Lange-Nielsen, 1957; Stubbs et al., 1976). This patient's markedly prolonged QT interval on admission shortened following the withdrawal of drugs and correction of hypokalaemia. However, in the absence of metabolic abnormalities and any drugs, the QT interval remained moderately prolonged 3 months later. This suggested that the patient had a long standing prolonged QT. It has been previously reported that the QT interval prolongs during identical atrial pacing following isoprenaline in patients with congenital long QT syndromes (Milne et al., 1982). In contrast, patients with acquired and idiopathic prolonged QT intervals have unaltered QT intervals after isoprenaline (Milne et al., 1982). The diagnosis of idiopathic prolonged QT in this patient was suggested by the response of the paced QT interval to isoprenaline and the absence of affected relatives.

Rapid weight loss in patients using liquid protein near starvation diets, has been reported to prolong the QT interval and induce torsade de pointes and sudden death (Brown et al., 1978; Isner et al., 1979). The pathogenesis remains unknown. This patient's weight loss was not rapid, and torsade de pointes has not been associated with less rigorous weight reduction diets.

Torsade de pointes has been described after the use

\section{References}

BAZETT, H.C. (1920). An analysis of the time relation of electrocardiograms. Heart, 7, 355.

BROWN, J.M., YETTER, J.F., SPICER, M.J. \& JONES, J.D. (1978). Cardiac complications of protein sparing modified fasting. Journal of the American Medical Association, 240, 120.

CURRY, P., FITCHETT, D., STUBBS, W. \& KRIKLER, D. (1976). Ventricular arrhythmias and hypokalaemia. Lancet, ii, 231.

FOWLER, N.O., MCCALL, D., CHOU, T., HOLMES, J.M.C. \& HANENSON, I.B. (1976). Electrocardiographic changes and cardiac arrhythmias in patients receiving psychotropic drugs. American Journal of Cardiology, 37, 223.

ISNER, J.M., SOURS, H.E., PARIS, A.L., FERRANS, V.J. \& ROBERTS, W.C. (1979). Sudden unexpected death in avid dieters using the liquid modified fast diet: observations in 17 patients and the role of the prolonged QT interval. Circulation, 60, 1401. of several drugs which prolong the QT interval, including class 1 antiarrhythmic drugs and phenoth-气̊ iazines (Fowler et al., 1976; Meltzer et al., 1978).3 Although diethylpropion hydrochloride has sympath- -2 omimetic actions it has not been reported to prolong. the QT interval (Schreiber et al., 1968). The drug has a $\vec{\Rightarrow}$ half life of $16 \mathrm{~h}$ and it is unlikely to have caused? persistent QT interval prolongation 3 months later. Furthermore, as sympathetic stimulation does noto prolong the QT interval in patients with idiopathic long QT syndrome, it is unlikely that diethylpropion hydrochloride contributed to the patient's markedlyes delayed repolarization at admission. However, sym- $\overrightarrow{0}$ pathetic stimulation with isoprenaline has been repor ted to further prolong repolarization in patients with $\vec{\omega}$ congenital long QT syndromes and diethylpropion? hydrochloride may further delay repolarization in this particular group of patients (Milne et al., 1982).

Hypokalaemia, hypomagnesaemia and, rarely, hy $-\stackrel{\sigma}{-}$ pocalcaemia have been associated with the induction of torsade de pointes in patients with QT abnor-or malities (Stubbs et al., 1976; Curry et al., 1976; Khan et $\stackrel{\oplus}{\oplus}$ al., 1981). Hypokalaemia, due to a variety ofo aetiologies, has been found to cause a high incidence of $\rightarrow$ arrhythmias when the plasma-potassium falls below 3 $3.2 \mathrm{mmol} / \mathrm{l}$, but there are few reports of life threatening arrhythmias (Curry et al., 1976). The incorrect use of diuretics and the development of hypokalaemia moy have facilitated the induction of torsade de pointesinn this patient with an underlying prolonged QT inter 1 and a predisposition to ventricular arrhythmias.

Following the correction of hypokalaemia ando withdrawal of drug, there was no spontaneous oro inducible ventricular arrhythmia. Therefore great cau- $\unrhd$ tion is required in the use of drugs which cause $\overrightarrow{\vec{O}}$ hypokalaemia or further delay ventricular repolariza- $\exists$ tion in patients with long QT intervals.
JERVELL, A. \& LANGE-NIELSEN, F. (1957). Congenital deaf mutism, functional heart disease with prolongation of Q-Tळ interval and sudden death. American Heart Journal, 54, 59.3

KHAN, M.M., LOGAN, K.R., McCOMB, J.M. \& ADGEY, A.A.O (1981). Management of recurrent ventricular tachyarr-כ hythmias associated with Q-T prolongation. American $\frac{7}{O}$ Journal of Cardiology, 47, 1301.

KOSSMAN, C.E. (1978). Torsade de pointes: an addition to the nosography of ventricular tachycardia. American Jour-o nal of Cardiology, 42, 1054.

KRIKLER, D.M. \& CURRY, P.V.L. (1976). Torsade de pointes, an atypical ventricular tachycardia. British Heart Journal,

MELTZER; R.S., ROBERT, E.W., MCMORROW, M. \& MAR- $\stackrel{\circ}{-}$ TIN, R.P. (1978). Atypical ventricular tachycardia as a manifestation of disopyramide toxicity. American Journal ${ }^{+}$ of Cardiology, 42, 1049.

MILNE, J.R., WARD, D., SPURRELL, R.A.J. \& CAMM, A.J. $\frac{\bar{D}}{\bar{D}}$ 
(1982). The long QT syndrome: effect of drugs and left stellate ganglion block. American Heart Journal, 104, 194. SCHREIBER, E.C., MIN, B.H., ZEIGER, A.V. \& LANG, J.F. (1968). Metabolism of diethylpropion hydrochloride-1-C $\mathrm{C}^{14}$ by the human. Journal of Pharmacology \& Experimental Therapeutics, 159, 372.
SOFFER, J. DREIFUS, L.S. \& MICHELSON, E.L. (1982). Polymorphous ventricular tachycardia associated with normal and long QT intervals. American Journal of Cardiology, 49, 2021.

STUBBS, W., FITCHETT, D. \& KRIKLER, D. (1976). Ventricular arrhythmias and hypokalaemia. Lancet, ii, 231. 